\title{
Treatment of Type I Diabetes using Autologous Adipose Derived Mesenchymal Stem Cells Translated to Insulin Secreting Islet like Cell Aggregates
}

\author{
Jaymesh M Thadani, Anant Marathe, Shivani Vakodikar, Prashant Kshatriya, Dhwani Modi, Rajni Vyas, \\ Bhaskar Vyas
}

Total Potential Cells (P) Ltd, $1^{\text {st }}$ floor Parimal Majumdar Wada, Pratap road, Raopura. Vadodara-390001. Gujarat, India.

\section{Corresponding Author:}

Dr. Anant Marathe

Email: dranantmarathe@hotmail.com

This is an Open Access article distributed under the terms of the Creative Commons Attribution License (creativecommons.org/ licenses/by/3.0).

Received : March 8, 2017

Accepted : June 2, 2017

Published : July 5, 2017

\begin{abstract}
Background: A number of papers describe different stem cell lines as the presenting feature to treat diabetes. Case Report: We report a 21 year old female with type 1 diabetes mellitus who was treated with islet like cell aggregates (ICAs) translated from autologous adipose derived mesenchymal stem cells (ADMSCs). Half of the total count of autologous adipose-derived stromal vascular fraction (AD-SVF) was injected intramuscularly. The other half was purified to ADMSCs and translated to ICAs and injected by intra-hepatic route. The patient showed remarkable decrease in her insulin requirement. No side effects were noted related to the treatment. Conclusion: The case study suggests AD-SVF and ADMSCs translated to ICAs is effective alternative strategy for the treatment of juvenile diabetes.
\end{abstract}

Keywords: Adioposity, Cell Line, Diabetes Mellitus, Mesenchymal Stomal Cells, Islets of Langerhans.

\section{Introduction}

Type 1 diabetes mellitus or juvenile diabetes (T1DM) develops as a result of $\mathrm{T}$ cell mediated autoimmune destruction of beta cells [1], characterized by insulin deficiency. Lifelong exogenous insulin supplementation and cadaveric islet transplantation are the only therapeutic option available at present. Insulin supplementation allows a reasonable control of blood sugar levels but at certain point of time they become insulin resistance [2]. The significant shortage of donor pancreas and usage of immune-suppression drugs is not a viable alternative [3]. Therefore a new alternative strategies emerged to treat type I diabetes. Mesenchymal stem cells (MSCs) are selfrenewable multi-potent, multi-lineage progenitor cells that have the potential to differentiate into various lineages [4]. They hone to the inflammatory region and are shown to exert profound antiinflammatory and immune-modulatory effects notably by cytokine and chemokine secretion. The lack of expression of MHC class II, absence of co-stimulatory molecules and HLA-DR negative surface marker; MSCs are immuno-naive [5].

MSCs have been expanded to cells deriving from all tissues including bone-marrow, muscle, adipose tissue, dental pulp and umbilical cord etc [6]. In the present case we have applied autologous adipose-derived stromal vascular fraction (AD-SVF) and autologous adipose derived mesenchymal stem cells (ADMSCs) translated to insulin secreting islet like cell aggregates (ICAs) [7]. ADMSCs translated to ICAs have been proved to be safe and effective in the pre-clinical studies [8]. ADMSCs express the transcription factor Isl-1 and Pax-6, which are critical transcription factors required for $\beta$ cell development [9]. Proliferative ADMSCs also express stem cell marker Nestin which is a multipotent pancreatic stem cell marker detected within pancreatic islets [10]. ADMSCs 
constitutively express glucagon and NeuroD as well as insulin [11]. We report a case of treatment of T1DM in 21 year old female using AD-SVF and ADMSCs translated to islet like cell aggregates (ICAs).

\section{Case Report}

A 21 year old female student pursuing Chartered Accountancy diagnosed with T1DM since 12 years presented with fatigue. She was lean, weighing 42 $\mathrm{kg}$ with 17.03 underweight BMI (Body Mass Index). The patient was less compliant with diabetic meal and routine physical exercise. This led to fatigue and her studies were getting adversely affected. She was on insulin of 24 units of Mixtard in the morning and 10 units in evening.

She had microcytic hypochromic anemia (hemoglobin $7.8 \mathrm{~g} / \mathrm{dL}$ ), with normal total leukocyte count, platelets and INR. Her fasting blood glucose was $167 \mathrm{mg} / \mathrm{dL}$ with glycosylated hemoglobin of 12.4 with mean blood glucose of $351 \mathrm{mg} / \mathrm{dL}$. Fasting urine did not have ketones. The patient was enrolled in clinical trial CTRI number 2013/02/004619. A written consent was obtained. The recruitment was open ended, nonrandomized and non-controlled. The Institutional Ethics Committee approval is obtained from DCGI Ref. No: ECR/201/Indt/GJ/2014.

Liposuction was done under local anesthesia by a trained plastic surgeon in operation theatre with specially designed aspiration cannulae and sedation. $100 \mathrm{cc}$ of lipo-aspirate was collected from lower abdominal fat and was transferred to a sterile container. The lipoaspirate was processed in GMP Class V laboratory for cell isolation under strict aseptic conditions. The protocol, images for ADMSCs isolation, phenotypic characterization and translation of ADMSCs to ICAs and immunocytochemistry of differentiated ICAs is cited in publication [12]. Five ICAs were picked manually from cultured plates. ICAs were fixed with freshly prepared $4 \%$ para-formaldehyde (PFA). Slides were prepared from the block so processed, and stained with DAPI for nuclear staining. Slides were observed under Carl Zeiss LSM 700 Confocal Microscope [Fig.1]. ADMSCs were differentiated into islet-like cell aggregates (ICA's) and showed positive staining for Dithizone demonstrating affinity for insulin [Fig.2].

The insulin secretion and glucose challenge study of ICAs was performed in vitro by increasing levels of glucose in the media and tested for insulin production. The study proved that ICAs respond to increased levels of glucose by increased secretion of insulin [Fig.3].

One half of SVF isolated, diluted in $4 \mathrm{cc}$ of Isolyte M, dosage of 2 million $/ \mathrm{kg}$ body weight,

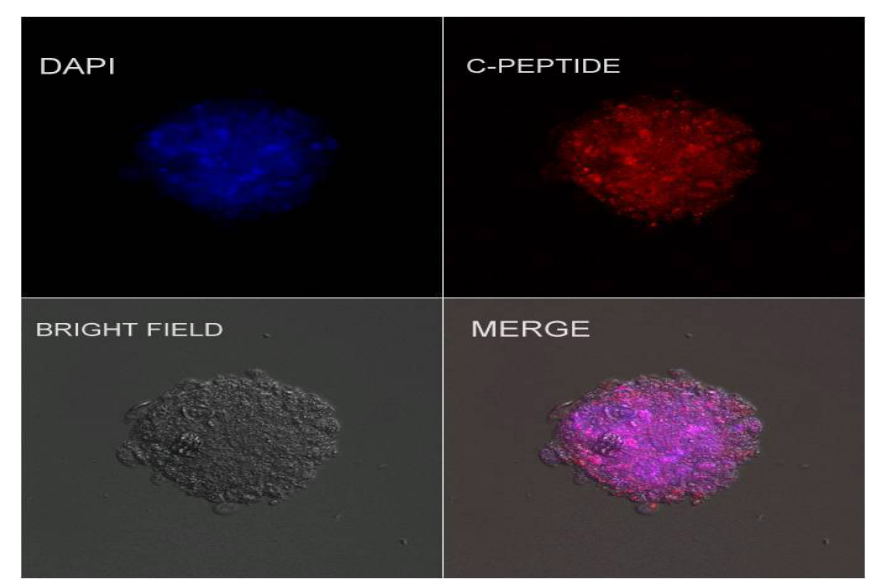

Fig.1: Merged image of ICA under confocal microscope.

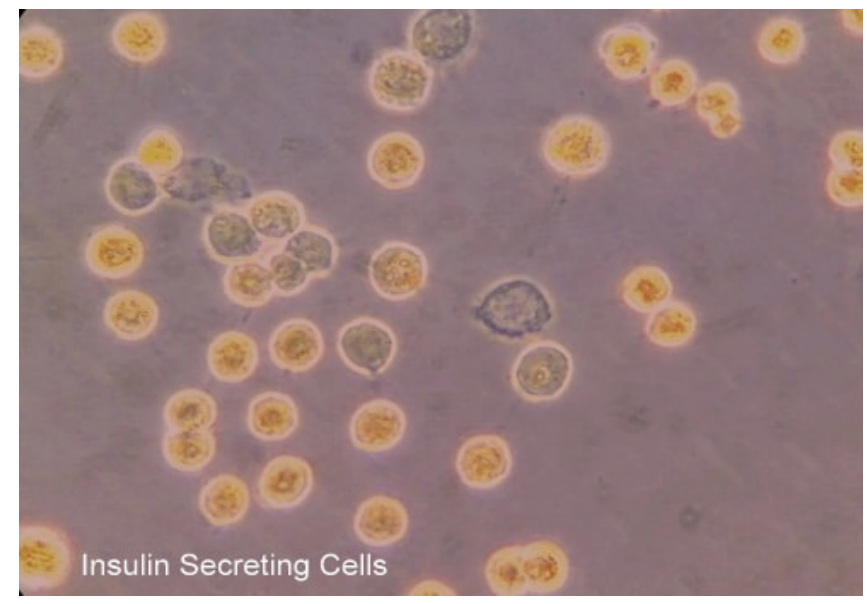

Fig.2: Dithizone staining of ICAs. 
were injected intramuscularly in each of deltoids and gluteus maximus muscles with 21 no. needle. Half of the SVF was processed for culture to get pure AD-MSCs. They were passaged twice to get more number of pure MSCs. After differentiation to ICAs, 100 ICAs were injected intra-hepatic using 21 no. spinal needle. The time interval between the intramuscular SVF injection and intra hepatic ICAs implantation was one month.

After the administration of AD-SVF and ADMSCs translated to ICAs, the clinical improvement was noted after three months. Her blood sugar dropped from $360 \mathrm{mg}$ to $260 \mathrm{mg}$. Her insulin requirement reduced to 16 units of Mixtard from 24 units in the morning and 10 units from 12 units in the evening. Her HBA1c level at 12 months had come down to $8.0 \%$ with the mean blood glucose level $269 \mathrm{mg} / \mathrm{dL}$. After the initial complains of restlessness, inactiveness and drowsiness, she started feeling better and her life style improved. She started feeling fresh, enthusiastic and was able to work for 8-10 hours in day. She continued her studies for chartered accountancy. She was advised high protein and high Omega 3 diet and was on iron and B-complex substitutes. She gained weight from $42 \mathrm{~kg}$ to $46 \mathrm{~kg}$; hemoglobin level increased from $7.8 \mathrm{gm} / \mathrm{dL}$ to $10.0 \mathrm{gm} / \mathrm{dL}$.

\section{Discussion}

Julio et al. reported safety and metabolic effect of autologous non-myeloablative hematopoietic stem cell in type I diabetes [13]. The autologous hematopoietic stem cells were collected from peripheral blood after injecting granulocyte colony stimulating factor. The cells were cryopreserved and injected intravenously. The immnosuppression drugs cyclophosphamide and antithymocyte globulin were used before injecting stem cells. In the present case report, safety and efficacy of autologous ADMSCs and ICAs were assessed. No adverse effects were observed related to ICA administration. Since the autologous ADMSCs are immuno-naive they do not need

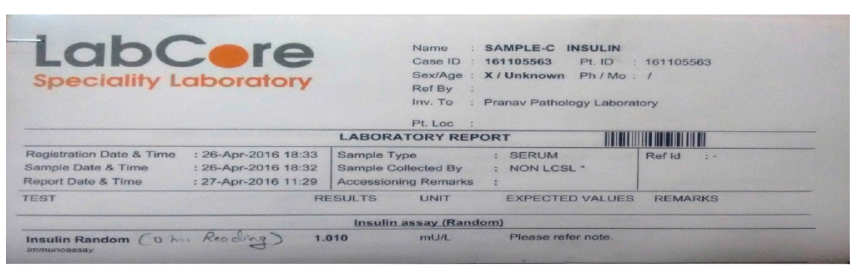

Fig.3(a): No Glucose - 0 hr Reading - 1.010

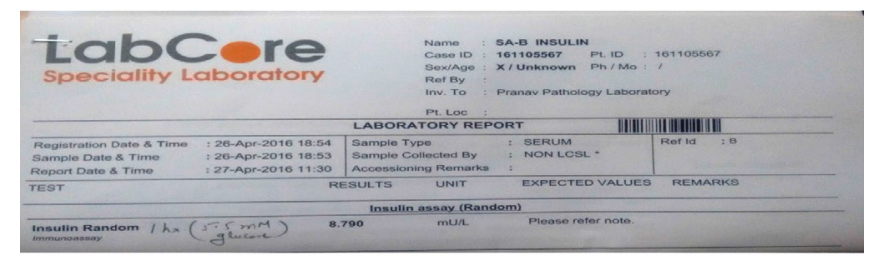

Fig.3(b): 5.5 mM Glucose - 1 hr Reading - 8.790

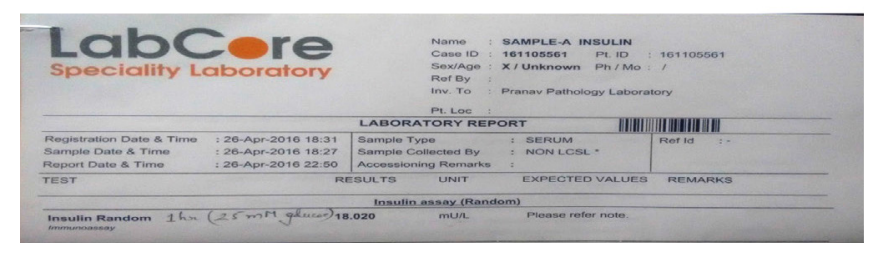

Fig.3(c): 25mM Glucose - 1 hr Reading - 18.020

immune suppression drugs. Moreover, freshly isolated SVF purified ADMSCs after 10 days and ADMSCs translated to ICAs after 20 days were injected. The cell viability of MSCs are reduced after cryopreservation and the potential to secrete insulin is reduced.

ADMSCs are better leveraged as a stem cell source for diabetic intervention as these are endowed with large number of bioactive mediators like Leptin, Adiponectin, and Visfatin, which are known to regulate glucose homeostasis [14]. Studies have also shown that the pancreatic transcription factors ISL1 and PAX6 are expressed in the proliferative population of ADMSCs [15]. Lin and Colleagues et al. reported that ADMSCs constitutively express glucagon and NeuroD as well as insulin [10]. We have achieved at our lab that ADMSCs are capable of differentiating into insulin-producing cells.

Timper et al. demonstrated the initial prospects of differentiating human ADMSCs into 
insulin, glucagon, and somatostatin expressing cells [11]. Three stage protocol by Chandra et al. 2011 entailing Activin A, Sodium butyrate, Taurine, GLP-Nicotinamide generated 51\% C-peptide cells, produces $400-600$ ICAs which is the maximum number of endocrine cells generated in any pancreatic differentiation study available till now. Autoimmune destruction of $\beta$-cells is a hallmark of T1DM. Immuno-modulatory and pro-angiogenic roles of MSCs are used in this protocol to arrest $\beta$-cell destruction, preserve residual $\beta$-cell mass and prevent disease recurrence [16]. We presume that increasing the number of ICAs may still bring better glucose control.

\section{Conclusion}

The stem cell based therapy helps prevent the autoimmune destruction of beta cells by immune modulation. AD-SVF and ADMSCs translated insulin producing ICAs supplement the insulin deficiency and helps improving the overall health in T1DM patient. Stem cell therapy thus can be a valuable approach in the treatment of T1DM. This will overcome the lack of donors for islet or pancreas transplantation.

Contributors: JMT: manuscript editing, literature search and case management; AM, SV, PK: manuscript writing, case management and literature search; DM, RV, BV: manuscript editing, intellectual inputs and funding. AM will act as guarantor. All authors approved the final version of the manuscript.

Funding: Small Business Innovation Research Initiative (SBIRI), BIRAC, GoI. Ref No: BT/SBIRI/1009/6-B20/2012; Competing interests: None stated.

\section{References}

1. American Diabetes Association. Diagnosis and classification of diabetes. Diabetes Care. 2004;27(suppl I):S5-S10.

2. Khoury N, McGill JB. Changes in insulin sensitivity following administration of the clinically-used lowdose pressor, norepinephrine. Diabetes Metab Res Rev. 2011;27:604-608.

3. Stratta RJ, Taylor RJ, Ozaki CF, Bynon JS, Miller SA, Baker TL, et al. The analysis of benefit and risk of combined pancreatic and renal transplantation versus renal transplantation alone. Surg Gynecol Obstet. 1993;177:163-171.
4. Tyndall A, Walker UA, Cope A, Dazzi F, De Bari $\mathrm{C}$, Fibbe $\mathrm{W}$, et al. Immunomodulatory properties of mesenchymal stem cells, Arthritis Research Therapy. 2005;9:301.

5. Mafi P, Hindocha S, Mafi R, Griffin M, Khan WS. Adult mesenchymal stem cells and cell surface characterization - A systematic review of the literature. Open Orthop J. 2011;5:253-260.

6. Da Silva Meirelles L, Chagastelles PC, Nardi NB. Mesenchymal stem cells reside in virtually all post-natal organs and tissues. J Cell Sci. 2006;119:2204-2213.

7. Paek HJ, Kim C, Williams SK. Adipose stem cellbased regenerative medicine for reversal of diabetic hyperglycemia World J Diabetes. 2014;5:235-243.

8. Chandra V, Swetha G, Muthyala S, Jaiswal AK, Bellare $\mathrm{JR}$, et al. Islet- like cell aggregates generated from human adipose tissue derived stem cells ameliorate experimental diabetes in mice. PLoS ONE 2011;6:20615.

9. Tung Dang LT, Tu Bui AN, Pham VM, Phan NK, Pham PV. Production of islet-like insulin-producing cell clusters in vitro from adipose-derived stem cells. Biomedical Research and Therapy. 2015;2:184-192.

10. Feng-Ping Lu, Kun-Pei Lin, Hsu-Ko Kuo. Diabetes and the Risk of Multi-System Aging Phenotypes: A Systematic Review and Meta-Analysis, PLOS. 2009;4: e4144.

11. Timper K, Seboek D, Eberhardt M, Linscheid P, Christ-Crain M, Keller U, et al. Human adipose tissuederived mesenchymal stem cells differentiate into insulin, somatostatin, and glucagon expressing cells, Biochemical and Biophysical Research Communications 2006;341:1135-1140.

12. Vyas BK, Vyas RB, Ansarullah A, Marathe A, Thadani $\mathrm{JM}$, Kshatriya $\mathrm{P}$, et al. Therapeutic application of autologous ADMSCS (Adipose Derived Mesenchymal Stem Cells) and Islet like Cell Aggregates (ICAS) derived from them in Type 1 and 2 diabetes mellitus A proof of concept study. J Stem Cell Res Dev Ther. 2016;3:08.

13. Voltarelli JC, Couri CEB, Stracieri ABPL, Oliveira MC, Daniela A. Moraes DA, Fabiano Pieroni, et al. Autologous Non-myeloablative Hematopoietic Stem Cell Transplantation in Newly Diagnosed Type 1 Diabetes Mellitus. JAMA. 2007;297:1568-1576.

14. Antuna-Puente B, Feve B, Fellahi S, Bastard JP. Adipokines: The missing link between insulin resistance and obesity. Diabetes Metab. 2008;34:2-11.

15. Kojima H, Fujimiya M, Matsumura K, Nakahara T, Hara M, Chan L. Extrapancreatic insulin-producing cells in multiple organs in diabetes. Proc Natl Acad Sci USA. 2004;101:2458-2463.

16. Ezquer M, Arango-Rodriguez M, Giraud-Billoud M, Ezquer F. Mesenchymal stem cell therapy in Type 1 Diabetes Mellitus and its main complications: From Experimental Findings to Clinical Practice. J Stem Cell Res Ther. 2014;4:8. 